International Journal of

Environmental Research and

Public Health

ISSN 1660-4601

www.mdpi.com/journal/ijerph

Article

\title{
Factors Associated with the Competencies of Public Health Workers in Township Hospitals: A Cross-Sectional Survey in Chongqing Municipality, China
}

\section{Zhifei He, Zhaohui Cheng, Hang Fu, Shangfeng Tang, Qian Fu, Haiqing Fang, Yue Xian, Hui Ming and Zhanchun Feng *}

School of Medicine and Health Management, Tongji Medical College, Huazhong University of Science and Technology, No. 13 Hangkong Rd., Wuhan, Hubei 430030, China;

E-Mails: houis123@163.com (Z.H.); czhbxt@163.com (Z.C.); tongjifh@163.com (H.F.); shangfenghust@sina.com (S.T.); sofureqian@hotmail.com (Q.F.); fanghaiqing.net@hust.edu.cn (H.F.); bantianxing@126.com (Y.X.); minghuitj@sina.com (H.M.)

* Author to whom correspondence should be addressed; E-Mail: zcfeng@hust.edu.cn; Tel.: +86-27-8369-2731.

Academic Editor: Paul B. Tchounwou

Received: 27 August 2015 / Accepted: 5 November 2015 / Published: 9 November 2015

Abstract: Purpose: This study aimed to explore the competencies of public health workers (PHWs) of township hospitals in Chongqing Municipality (China), and determine the related impact factors of the competencies of PHWs; Methods: A cross-sectional research was conducted on 314 PHWs from 27 township hospitals in three districts in Chongqing Municipality (China), from June to August 2014. A self-assessment questionnaire was established on the basis of literature reviews and a competency dictionary. The differences in competencies among the three districts were determined by adopting the chi-square test, $\mathrm{t}$-test, analysis of variance (ANOVA) method, and the impact factors of the competencies of PHWs were determined by adopting stepwise regression analysis. Results: (1) Results of the demographic characteristics of PHWs in three sample districts of Chongqing Municipality showed that a significant difference in age of PHWs $(p=0.021<0.05)$ and the majors of PHWs ( $p=0.045<0.05$ ); (2) In terms of the self-evaluation competency results of PHWs in township hospitals, seven among the 11 aspects were found to have significant differences in the three districts by the ANOVA test; (3) By adopting the t-test and ANOVA method, results of the relationship between the characteristics of PHWs and their competency scores 
showed that significant differences were found in the economic level $(p=0.000<0.05)$, age $(p=0.000<0.05)$, years of working $(p=0.000<0.05)$ and title of PHWs $(p=0.000<0.05)$; (4) Stepwise regression analysis was used to determine the impact factors of the competencies of PHWs in township hospitals, including the economic level $(p=0.000<0.001)$, years of working $(p=0.000<0.001)$, title $(p=0.001<0.005)$, and public health major $(p=0.007$ $<0.01)$. Conclusions: The competencies of the township hospital staff in Chongqing Municipality (China), are generally insufficient, therefore, regulating the medical education and training skills of PHWs is crucial to improve the competencies of PHWs in the township hospitals of Chongqing Municipality. The results of this study can be mirrored in other areas of China.

Keywords: competencies; public health workers; township hospitals; impact factors; Chongqing Municipality

\section{Introduction}

The health system serves a population of 1.3 billion in China, which is the World's largest population [1]. The primary health care (PHC) system is the main component of China's health system. Large numbers of studies [2,3] have shown that a good PHC system improves population health and estimates the gaps in health caused by disparities in socioeconomic status. Township hospitals as key providers of PHC play a crucial role in the three-level network of rural public health in China. Currently, township hospitals in China experience human resources shortage and insufficient abilities [4]. The 11th "five-year plan" of health programmers in China includes several strategies that will be beneficial for public health workers at all levels [5]. PHWs are the direct providers of health service, and they determine the quantity, quality, style and cost of public health service [6]. The competencies of PHWs of township hospitals play an irreplaceable role in the primary public health system and the need for competent public health professionals increases day by day [7].

In 1973, McClelland published a paper entitled "Testing for Competence Rather than for Intelligence", and it indicated that the concept of competencies involves the knowledge, skills, abilities and characteristics of outstanding individuals [8]. McLagan argued that competencies involve individuals who could finish the main job with knowledge, skills and abilities [9]. Boyatzis explained that competency is a kind of ability that could meet the organizational environment needs [10]. Spencer found competency is an individual's deeper and potential features [11]. Although competency has many definitions, competency generally indicates that an individual's deeper characteristics can differentiate elitists from ordinary workers, and those characteristics include the motivation, peculiarity, self-image, attitude and value, knowledge, perceived quality, and skills.

Chongqing Municipality is located in Western China. According to a previous study, the ratio per 1000 rural population of township hospitals staff is low in Western China, and in 2013, the ratio of township hospital staff was only 2.15 workers per 1000 rural population [12]. Chongqing Municipality only reached half of the average number of national PHWs in township hospitals [12]. At the same time, the structure of PHWs is inappropriate and personnel utilization was inefficient [13]. Moreover, the loss 
of staff in township hospitals is serious, with some of the remaining staff lacking work capability [14]. With the development of public health, the personal quality of public health workers is an irreplaceable impact factor of township hospitals in rural China $[4,15,16]$. The public health workforce is faced with many challenges, such as a diminishing number of workers due to the great number of retiring public health workers [17], job losses associated with budget cuts [18], non-competitive salaries and benefits that cause difficulty in recruiting new workers [18], and limited formal public health training for public health workers among others [19]. Therefore, the need for the competency of PHWs is so urgent that it can influence the performance of township hospitals. According to a study, the concept of competency encompasses the combination of skills, performance, and daily behavior [20]. Competency provides a framework for practice standards designed to assist new practitioners in a specialization to develop necessary skills [21].

Aside from external factors, such as the environment, social culture, and economic level that can influence a hospital's efficiency, the competencies of PHWs in township hospitals also play a more vital role in influencing a hospital's efficiency [22]. According to the classification of competency, the health system mainly focuses on leader's competency, such as the competency of the directors of hospitals [23], the director of the Center for Disease Control (CDC), and the principals of the Community Health Service Centers and township hospitals [24]. However, studies on the core competencies and professional competencies of PHWs in township hospitals in China are limited [25]. The competencies of PHWs in township hospitals in rural China are so vital that they can decide the development level of one township hospital [26]. This study focuses on the competencies of PHWs of township hospitals in Chongqing Municipality (China), and determines the relative impact factors of the competencies of PHWs. The competencies not only improve the professional abilities and skills of PHWs in sample areas but also serve as reference for enhancing the working abilities of PHWs of other township hospitals in rural China.

\section{Methods}

\subsection{Sample Method}

This cross-sectional survey was conducted from June to August 2014 in Chongqing Municipality (China). A multistage stratified purposive sampling method was adopted (Table 1).

Table 1. Sampling strategy and achieved sample size by area.

\begin{tabular}{cccccc}
\hline \multirow{2}{*}{ Province } & Districts & Income Level & $\begin{array}{c}\text { Participating } \\
\text { Hospitals }\end{array}$ & $\begin{array}{c}\text { Sample Size } \\
\text { PHWs (\%) }\end{array}$ & $\begin{array}{c}\text { Total PHWs } \\
\text { Size (\%) }\end{array}$ \\
\hline \multirow{2}{*}{ Chongqing } & Jiulongpo & Developed & 9 township hospitals & $100(31.85)$ & $118(34.40)$ \\
Municipality & Qianjiang & Middle economic level & 9 township hospitals & $107(34.08)$ & $110(32.07)$ \\
& Hechuan & Underdeveloped & 9 township hospitals & $107(34.08)$ & $115(33.53)$ \\
\hline
\end{tabular}


The regions surveyed were divided into three types of districts based on economic conditions [27], including developed district (Jiulongpo), district of middle economic level (Qianjiang), and economically underdeveloped district (Hechuan). Nine township hospitals were selected in each sample district, and the total number of township hospitals was 27. A questionnaire survey was conducted on PHWs in the 27 township hospitals (343 PHWs). The valid number of sample PHWs was 314.

\subsection{Survey Content}

A "Competencies of PHWs of Township Hospitals" questionnaire was designed. The questionnaire included two parts: the demographic characteristics of the PHWs in township hospitals (i.e., name, age, gender, educational background, major, and title) and the competencies of PHWs. According to some related studies and a competency dictionary [28-31], we selected 11 aspects of competencies from 20 aspects. We designed two relevant questions for each aspect. Overall, 22 questions of 11 aspects were obtained. Based on the Likert scale, we designed four alternative options for each question, with each option representing a score (definitely low, 1 score; low, 2 score; possible high, 3 score; high, 4 score). A higher score represented a higher level. The highest score was 88 points (full score), whereas the lowest score was 22 points. We tested the second part of the questionnaire, and the Cronbach's alpha coefficient was 0.808 . The reliability of the questionnaire was acceptable because the Cronbach's alpha coefficient is higher than 0.7 [32,33], and the questionnaire was recognized by health professors.

\subsection{Survey Methodology}

Trained and qualified investigators were separately sent to each township hospital. The personnel in charge of the PHS gathered the health workers in the township hospitals, and then the investigators described the purpose of the survey to the hospital staff. Those who agreed to take part in the survey were supplied with the (anonymous) self-administered questionnaires. Completed questionnaires were collected and checked at the scene.

\subsection{Statistical Analysis}

Data entry was performed using Excel and Epidata. A double-entry method was adopted to ensure the accuracy of the data. SPSS 19.0 statistical software (Version 19.0; SPSS Inc., Chicago, IL, USA) was used for statistical analysis. The factors of PHWs in township hospitals were identified by the descriptive statistics method. The competencies of PHWs in three districts were the compared using the chi-square test, ANOVA and $t$-test. The associated impact factors of the competencies of PHWs were identified by adopting the stepwise regression analysis method. The stepwise regression analysis model belongs to multiple linear regression model, which determined the dependent relationship among variables. According to related research, we consider the score of self-evaluation competencies as the dependent variable and the factors of economic level, years of working, title and major as the independent variables [15]. 


\subsection{Results}

Characteristics of the Sample

Characteristics of the study sample are shown in Table 2. Among the 343 survey questionnaires of PHWs in the 27 township hospitals, 314 (91.55\%) were completed and 29 were incomplete. Among the 314 respondents, 161 (51.3\%) were male and 153 (48.7\%) were female PHWs. In terms of location, 100 PHWs were in Jiulongpo District, 107 in Qianjiang District and 107 in Hechuan District. No significant difference was found among the three districts $(p=0.883>0.05)$ in terms of gender. A significant difference was found among the four age groups $(p=0.021<0.05)$. Among the PHWs, $110(35.0 \%)$ were aged 31 to 40 years, and $113(36.0 \%)$ were aged 41 to 50 years. These two age groups accounted for the largest proportion among the four age groups. Specifically, the 31-40 age group accounted for the largest proportion among the four age groups (45.0\%) in Jiulongpo, and the 41-50 age group accounted for the largest proportion in Qianjiang and Hechuan, at 35.5\% and $42.1 \%$, respectively. We divided years of working into four groups, and no significant difference was found among them $(p=0.195>0.05)$. Two groups had the largest ratio: the group of $107(34.1 \%)$ PHWs who worked for less than 10 years, and the group of 114 (36.3\%) PHWs who worked from 11 to 20 years. No significant difference was found among the three educational background groups $(p=0.369>0.05)$. Among the PHWs, 107 (34.1\%) had a junior high school educational degree, 119 (37.9\%) had a senior high school educational degree, and 88 (28.0\%) had a college educational degree. The PHWs had five groups of majors, with $27.1 \%$ of them specializing in clinical work, $25.8 \%$ in nursing and $24.2 \%$ in public health (full-time public health workers in township hospitals). A significant difference was found among the five major groups $(p=0.045<0.05)$. In particular, the number of public health majors was the largest $(33.0 \%)$ in Jiulongpo District, and the number of clinical majors was the largest in Qianjiang and Hechuan, at $27.1 \%$ and $29.9 \%$, respectively. The title of the PHWs focused on the junior and middle levels, for a total rate of 75.2\%. Among the PHWs, 13 (4.1\%) had a senior qualification title, and $65(20.7 \%)$ did not have any title. No significant difference was found among them $(p=0.142>0.05)$.

\subsection{Self-Evaluation Competencies of PHWs in Township Hospitals}

In terms of the self-evaluation competencies of PHWs in township hospitals, we adopted the ANOVA method to analyze the scores of PHWs in the three districts (Table 3). The 11 aspects were achievement orientation $(\mathrm{ACH})$, performance orientation (PMO), detailed test objectives (DTO), action (ACT), learning (LRN), flexible and adaptive (FAA), teamwork (TMW), public relations ability (PLR), focusing on the service objectives (CMF), communication (CMC), and responsibility (RSP). Each aspect has two related titles, and each question has a score. In this study, we calculated the mean sores and compared them among the three different districts using ANOVA. Among the 11 aspects (22 questions), seven aspects had mean scores with significant differences: PMO $(p=0.026<0.01)$, ACT $(p=0.002<0.01)$, LRN $(p=0.013<0.01)$, FAA $(p=0.002<0.01)$, PLR $(p=0.005<0.01)$, CMF $(p=0.000<0.001)$, and CMC $(p=0.002<0.01)$. In the aspect of PMO, the mean score of competencies of PHWs in Jiulongpo was higher than that of PHWs in Hechuan (1)>3). The mean score of ACT competencies of PHWs in Jiulongpo was higher than that of PHWs in Qianjiang. The mean score of ACT competencies of PHWs in Hechuan was higher than that of PHWs in Qianjiang, but no significant difference was found 
between Qianjiang and Hechuan (1)>2(2), (3) $>$ (2). The mean score of LRN competencies was higher in Jiulongpo than those in Qianjiang and Hechuan. No significant difference was found between Qianjiang and Hechuan (1)>(2), (1)>3). As shown in Table 3, significant differences were found in the mean scores of FAA competencies, PLR competencies, and CMC competencies. (1) $>$ (2), (1) $>$ (3), $p<0.01)$. The mean score of CMF competencies was higher in Jiulongpo than that in Qianjiang and Hechuan (1) $>$ (2), (1)>3, $p<0.001$ ). Overall, significant differences were found in the PHWs' competency scores among the three districts $(p=0.000<0.005$; (1) $>$ (2), (1) $>$ (3)).

Table 2. Demographic characteristics of the PHWs in township hospitals.

\begin{tabular}{|c|c|c|c|c|c|c|c|c|c|}
\hline \multirow{2}{*}{ Characteristics } & \multicolumn{2}{|c|}{ Total } & \multicolumn{2}{|c|}{ Jiulongpo } & \multicolumn{2}{|c|}{ Qianjiang } & \multicolumn{2}{|c|}{ Hechuan } & \multirow{2}{*}{$p$} \\
\hline & $N=314$ & $\%$ & $N=100$ & $\%$ & $N=107$ & $\%$ & $N=107$ & $\%$ & \\
\hline \multicolumn{10}{|l|}{ Gender } \\
\hline Male & 161 & $51.3 \%$ & 53 & $53.0 \%$ & 53 & $49.5 \%$ & 55 & $51.4 \%$ & \multirow{2}{*}{0.883} \\
\hline Female & 153 & $48.7 \%$ & 47 & $47.0 \%$ & 54 & $50.5 \%$ & 52 & $48.6 \%$ & \\
\hline \multicolumn{10}{|l|}{ Age } \\
\hline $20-30$ & 73 & $23.2 \%$ & 22 & $22.0 \%$ & 25 & $23.4 \%$ & 26 & $24.3 \%$ & \multirow{4}{*}{$0.021 *$} \\
\hline $31-40$ & 110 & $35.0 \%$ & 45 & $45.0 \%$ & 32 & $29.9 \%$ & 33 & $30.8 \%$ & \\
\hline $41-50$ & 113 & $36.0 \%$ & 30 & $30.0 \%$ & 38 & $35.5 \%$ & 45 & $42.1 \%$ & \\
\hline $51-60$ & 18 & $5.7 \%$ & 3 & $3.0 \%$ & 12 & $11.2 \%$ & 3 & $2.8 \%$ & \\
\hline \multicolumn{10}{|l|}{ Years of working } \\
\hline $1-10$ & 107 & $34.1 \%$ & 37 & $37.0 \%$ & 41 & $38.3 \%$ & 29 & $27.1 \%$ & \multirow{4}{*}{0.195} \\
\hline $11-20$ & 114 & $36.3 \%$ & 39 & $39.0 \%$ & 30 & $28.0 \%$ & 45 & $42.1 \%$ & \\
\hline $21-30$ & 82 & $26.1 \%$ & 22 & $22.0 \%$ & 30 & $28.0 \%$ & 30 & $28.0 \%$ & \\
\hline $31-40$ & 11 & $3.5 \%$ & 2 & $2.0 \%$ & 6 & $5.6 \%$ & 3 & $2.8 \%$ & \\
\hline \multicolumn{10}{|c|}{ Educational background } \\
\hline Junior high school & 107 & $34.1 \%$ & 26 & $26.0 \%$ & 41 & $38.3 \%$ & 40 & $37.4 \%$ & \multirow{3}{*}{0.369} \\
\hline Senior high school & 119 & $37.9 \%$ & 37 & $37.0 \%$ & 40 & $37.4 \%$ & 42 & $39.3 \%$ & \\
\hline College/University & 88 & $28.0 \%$ & 37 & $37.0 \%$ & 26 & $24.3 \%$ & 25 & $23.4 \%$ & \\
\hline \multicolumn{10}{|l|}{ Major } \\
\hline Clinic & 85 & $27.1 \%$ & 24 & $24.0 \%$ & 29 & $27.1 \%$ & 32 & $29.9 \%$ & \multirow{5}{*}{$0.045 *$} \\
\hline Nursing & 81 & $25.8 \%$ & 22 & $22.0 \%$ & 28 & $26.2 \%$ & 31 & $29.0 \%$ & \\
\hline Public health & 76 & $24.2 \%$ & 33 & $33.0 \%$ & 24 & $22.4 \%$ & 19 & $17.8 \%$ & \\
\hline Maternal & 43 & $13.7 \%$ & 11 & $11.0 \%$ & 18 & $16.8 \%$ & 14 & $13.1 \%$ & \\
\hline Others & 29 & $9.2 \%$ & 10 & $10.0 \%$ & 8 & $7.5 \%$ & 11 & $10.3 \%$ & \\
\hline \multicolumn{10}{|l|}{ Title } \\
\hline None & 65 & $20.7 \%$ & 12 & $12.0 \%$ & 21 & $19.6 \%$ & 32 & $29.9 \%$ & \multirow{4}{*}{0.142} \\
\hline Junior & 134 & $42.7 \%$ & 42 & $42.0 \%$ & 47 & $43.9 \%$ & 45 & $42.1 \%$ & \\
\hline Middle & 102 & $32.5 \%$ & 41 & $41.0 \%$ & 34 & $31.8 \%$ & 27 & $25.2 \%$ & \\
\hline Senior & 13 & $4.1 \%$ & 5 & $5.0 \%$ & 5 & $4.7 \%$ & 3 & $2.8 \%$ & \\
\hline
\end{tabular}

The $p$ value was calculated by chi-square test, $* p<0.05$. 
Table 3. The scores of self-evaluation competencies of PHWs in township hospitals.

\begin{tabular}{|c|c|c|c|c|c|c|c|c|c|}
\hline \multirow[t]{2}{*}{ Aspects } & \multirow[t]{2}{*}{ Questions } & \multicolumn{2}{|c|}{$\begin{array}{c}\text { Jiulongpo } \\
\text { (1)(High) }\end{array}$} & \multicolumn{2}{|c|}{$\begin{array}{l}\text { Qianjiang } \\
\text { (2)(Middle) }\end{array}$} & \multicolumn{2}{|c|}{ Hechuan (3)(Low) } & \multirow[t]{2}{*}{$p$} & \multirow[t]{2}{*}{ LSD } \\
\hline & & Mean & SD & Mean & SD & Mean & SD & & \\
\hline \multirow{3}{*}{$\mathrm{ACH}$} & Inner motivation & 3.60 & 0.49 & 3.64 & 0.48 & 3.67 & 0.47 & 0.549 & \\
\hline & High standard & 3.72 & 0.45 & 3.71 & 0.46 & 3.68 & 0.47 & 0.826 & \\
\hline & Mean & 7.32 & 0.72 & 7.36 & 0.66 & 7.36 & 0.77 & 0.922 & \\
\hline \multirow{3}{*}{ PMO } & Performance be tracked & 3.72 & 0.45 & 3.60 & 0.49 & 3.57 & 0.50 & 0.062 & \\
\hline & performance be enhanced & 3.18 & 0.39 & 3.18 & 0.47 & 3.07 & 0.54 & 0.131 & (1) $>$ (3) $* *$ \\
\hline & Mean & 6.90 & 0.61 & 6.78 & 0.73 & 6.64 & 0.74 & $0.026 * *$ & \\
\hline \multirow{3}{*}{ DTO } & Details & 3.50 & 0.50 & 3.22 & 0.42 & 3.38 & 0.49 & 0.000 & \\
\hline & Precise working & 3.19 & 0.39 & 3.30 & 0.46 & 3.23 & 0.43 & 0.183 & \\
\hline & Mean & 6.69 & 0.60 & 6.52 & 0.63 & 6.62 & 0.64 & 0.158 & \\
\hline \multirow{3}{*}{ ACT } & Initiative & 3.24 & 0.43 & 3.17 & 0.38 & 3.19 & 0.39 & 0.410 & \\
\hline & Impetus & 3.81 & 0.39 & 3.58 & 0.50 & 3.76 & 0.43 & 0.001 & (1) $>$ (2) $* * *$, (3) $>$ (2) ** \\
\hline & Mean & 7.05 & 0.61 & 6.75 & 0.60 & 6.94 & 0.64 & $0.002 * *$ & \\
\hline \multirow{3}{*}{ LRN } & Summary of experience & 3.84 & 0.37 & 3.79 & 0.41 & 3.76 & 0.43 & 0.336 & \\
\hline & Gap analysis & 3.80 & 0.40 & 3.60 & 0.49 & 3.67 & 0.47 & 0.007 & (1) $>$ (2) $* *,(1)>(3) * *$ \\
\hline & Mean & 7.64 & 0.58 & 7.39 & 0.67 & 7.43 & 0.67 & $0.013 * *$ & \\
\hline \multirow{3}{*}{ FAA } & Decision making & 3.47 & 0.50 & 3.43 & 0.50 & 3.50 & 0.50 & 0.550 & \\
\hline & Frustration tolerance & 3.86 & 0.38 & 3.55 & 0.57 & 3.56 & 0.54 & 0.000 & (1) $>$ (2) $* *,(1)>(3) * *$ \\
\hline & Mean & 7.33 & 0.59 & 6.98 & 0.81 & 7.07 & 0.80 & $0.002 * *$ & \\
\hline \multirow{3}{*}{ TMW } & Role adjustment & 3.32 & 0.47 & 3.28 & 0.45 & 3.20 & 0.42 & 0.126 & \\
\hline & Technical support & 3.37 & 0.49 & 3.27 & 0.45 & 3.35 & 0.48 & 0.284 & \\
\hline & Mean & 6.69 & 0.72 & 6.55 & 0.62 & 6.54 & 0.70 & 0.222 & \\
\hline \multirow{3}{*}{ PLR } & Interpersonal influence & 3.44 & 0.50 & 3.32 & 0.47 & 3.34 & 0.47 & 0.148 & \\
\hline & Conflict management & 3.49 & 0.50 & 3.31 & 0.46 & 3.38 & 0.49 & 0.027 & (1) $>$ (2) $* *,(1)>$ (3) $* *$ \\
\hline & Mean & 6.93 & 0.66 & 6.63 & 0.68 & 6.72 & 0.70 & $0.005 * *$ & \\
\hline \multirow{3}{*}{$\mathrm{CMF}$} & Concern service objects & 3.72 & 0.45 & 3.56 & 0.50 & 3.55 & 0.50 & 0.021 & \\
\hline & Develop service objects & 3.88 & 0.33 & 3.64 & 0.48 & 3.68 & 0.47 & 0.000 & (1) $>$ (2) $* * *$, (1) $>$ (3) $* * *$ \\
\hline & Mean & 7.60 & 0.55 & 7.21 & 0.74 & 7.23 & 0.67 & $0.000 * * *$ & \\
\hline \multirow{3}{*}{$\mathrm{CMC}$} & Positive interaction & 3.80 & 0.40 & 3.78 & 0.42 & 3.80 & 0.40 & 0.862 & \\
\hline & Mechanism assurance & 3.31 & 0.46 & 3.08 & 0.28 & 3.11 & 0.32 & 0.000 & (1) $>$ (2) $* *,(1)>(3) * *$ \\
\hline & Mean & 7.11 & 0.62 & 6.86 & 0.46 & 6.92 & 0.48 & $0.002 * *$ & \\
\hline \multirow{3}{*}{ RSP } & Responsibility cognition & 3.28 & 0.45 & 3.18 & 0.38 & 3.23 & 0.43 & 0.215 & \\
\hline & Consciousness & 3.73 & 0.45 & 3.72 & 0.45 & 3.73 & 0.45 & 0.983 & \\
\hline & Mean & 7.01 & 0.72 & 6.90 & 0.66 & 6.96 & 0.71 & 0.504 & \\
\hline Total & & 78.27 & 2.67 & 75.92 & 3.35 & 76.42 & 2.50 & $0.000 * * *$ & (1) $>$ (2) $* * *$, (1) $>$ (3) $* * *$ \\
\hline
\end{tabular}

The mean scores were test with ANOVA method. * $p<0.05, * * p<0.01, * * * p<0.001$.

\subsection{Relationship between the Factors of PHWs and Self-Evaluation Competencies}

In terms of the relationship between the factors (independent variables) of PHWs and the self-evaluation competencies of PHWs (Table 4), the results indicated that gender and educational background had no 
significant differences. A positive relationship was found between age and self-evaluation competencies of PHWs $(\mathrm{F}=13.11, p=0.000<0.001)$. The $51-60$ age group obtained the highest score. A significant difference was found between years of working and the self-evaluation competencies of PHWs $(\mathrm{F}=15.51, p=0.000<0.001)$. The years of working of the $31-40$ age group obtained the highest score. For the majors of PHWs, professional public health workers had the highest score $(\mathrm{F}=3.91, p=0.004$ $<0.001$ ).in terms of the title of PHWs, public health workers who had an advanced title obtained the highest score among the four groups $(\mathrm{F}=11.64, p=0.000<0.001)$.

Table 4. Relationship between factors of PHWs and self-evaluated competencies.

\begin{tabular}{|c|c|c|c|c|c|c|}
\hline Items & $n$ & Mean & $S D$ & t/F Value & $p$ & $L S D$ \\
\hline \multicolumn{7}{|l|}{ Sex } \\
\hline Male & 161 & 76.88 & 2.91 & \multirow[t]{2}{*}{$t=0.265$} & \multirow[t]{2}{*}{0.415} & \\
\hline Female & 153 & 76.79 & 3.16 & & & \\
\hline \multicolumn{7}{|l|}{ Economic level } \\
\hline (1)Hechuan & 107 & 76.42 & 2.499 & \multirow[t]{3}{*}{$\mathrm{F}=19.13 * * *$} & \multirow[t]{3}{*}{0.000} & \\
\hline (2)Qianjiang & 107 & 75.92 & 3.354 & & & (3) $>$ (1), (3) $>$ (2) \\
\hline (3) Jiulongpo & 100 & 78.27 & 2.666 & & & \\
\hline \multicolumn{7}{|l|}{ Age } \\
\hline (1) $20-30$ & 73 & 75.22 & 3.42 & \multirow[t]{4}{*}{$\mathrm{F}=13.711 * * *$} & \multirow[t]{4}{*}{0.000} & \\
\hline (2) $31-40$ & 110 & 77.19 & 2.85 & & & \\
\hline (3) $41-50$ & 113 & 77.12 & 2.45 & & & $(4)>(2),(3),(1)$ \\
\hline (4) $51-60$ & 18 & 79.44 & 2.87 & & & \\
\hline \multicolumn{7}{|l|}{ Years of working } \\
\hline (1) $1-10$ & 107 & 75.51 & 3.39 & \multirow[t]{4}{*}{$\mathrm{F}=15.507 * * *$} & \multirow[t]{4}{*}{0.000} & \\
\hline (2) $11-20$ & 114 & 77.46 & 2.71 & & & \\
\hline (3) $21-30$ & 82 & 77.23 & 2.07 & & & $(4)>(2),(3),(1)$ \\
\hline (4) $31-40$ & 11 & 80.27 & 3.17 & & & \\
\hline \multicolumn{7}{|l|}{ Educational background } \\
\hline (1)Junior high school & 107 & 77.37 & 2.36 & \multirow[t]{3}{*}{$\mathrm{F}=2.583$} & \multirow[t]{3}{*}{0.077} & / \\
\hline (2) Senior high school & 119 & 76.53 & 2.99 & & & \\
\hline (3)College/ University & 88 & 76.60 & 3.68 & & & \\
\hline \multicolumn{7}{|l|}{ Major } \\
\hline (1)Clinic & 85 & 76.55 & 2.68 & \multirow[t]{5}{*}{$\mathrm{F}=3.907 * * *$} & \multirow[t]{5}{*}{0.004} & \\
\hline (2) Nursing & 81 & 76.17 & 2.79 & & & \\
\hline (3) Public health & 76 & 77.93 & 3.17 & & & (3) $>$ (4), (1), (5), (2) \\
\hline (4) Maternal & 43 & 76.95 & 2.92 & & & \\
\hline (5) Others & 29 & 76.48 & 3.78 & & & \\
\hline \multicolumn{7}{|l|}{ Title } \\
\hline (1)None & 65 & 75.49 & 2.94 & \multirow[t]{4}{*}{$\mathrm{F}=11.641 * * *$} & \multirow[t]{4}{*}{0.000} & \multirow{4}{*}{ (4) $>(3),(2),(1)$} \\
\hline (2) Junior & 134 & 76.68 & 3.04 & & & \\
\hline (3) Senior & 102 & 77.51 & 2.68 & & & \\
\hline (4)Advanced & 13 & 79.92 & 2.50 & & & \\
\hline
\end{tabular}

The significant differences were tested with t-test and ANOVA analysis, $* * * p<0.001$. 


\subsection{Impact Factors of Self-Evaluation Competencies}

Stepwise regression was used to further analyze the factors affecting the competencies of PHWs. Results are shown in Table 5. Related literature showed that the factors associated with the general competencies by the multivariable model — age group, education, years of working and title - are the independent variables [34-36]. In this study, the economic level of the three districts $(p=0.000<0.001)$, years of working of PHWs $(p=0.000<0.001)$, title of PHWs $(p=0.001<0.005)$ had significant differences with the self-evaluation competencies of PHWs. In terms of majors, the public health major indicated a significant difference $(p=0.007<0.01)$.

Table 5. Stepwise regression analysis of factors related to self-evaluation competencies $(N=314)$.

\begin{tabular}{|c|c|c|c|c|c|c|c|c|c|}
\hline \multirow[t]{2}{*}{ Variables } & \multirow[t]{2}{*}{ B } & \multirow{2}{*}{$\begin{array}{l}\text { Std. } \\
\text { Error }\end{array}$} & \multirow[t]{2}{*}{$\boldsymbol{\beta}$} & \multirow[t]{2}{*}{$t$ value } & \multirow[t]{2}{*}{$p$} & \multicolumn{2}{|c|}{$\begin{array}{c}95.0 \% \\
\text { Confidence } \\
\text { Interval for B }\end{array}$} & \multirow[t]{2}{*}{$\mathbf{R}^{2}$} & \multirow[t]{2}{*}{$\mathbf{F}$} \\
\hline & & & & & & $\begin{array}{l}\text { Lower } \\
\text { Bound }\end{array}$ & $\begin{array}{l}\text { Upper } \\
\text { Bound }\end{array}$ & & \\
\hline Constant & 71.725 & 0.608 & & $118.047 * * *$ & 0.000 & & & $0.216 *$ & $21.221 * * *$ \\
\hline Economic level & 0.786 & 0.195 & 0.211 & $4.031 * * *$ & 0.000 & 0.403 & 1.170 & & \\
\hline Years of working & 0.925 & 0.186 & 0.263 & $4.961 * * *$ & 0.000 & 0.558 & 1.291 & & \\
\hline Title & 0.672 & 0.201 & 0.180 & $3.344 * * *$ & 0.001 & 0.276 & 1.067 & & \\
\hline \multicolumn{10}{|l|}{ Major } \\
\hline Nursing & & & -0.092 & -1.710 & 0.088 & & & & \\
\hline public health & 0.983 & 0.361 & 0.139 & $2.722 * *$ & 0.007 & 0.272 & 1.694 & & \\
\hline Maternal & & & 0.068 & 1.288 & 0.199 & & & & \\
\hline Others & & & 0.033 & 0.635 & 0.526 & & & & \\
\hline
\end{tabular}

\section{Discussion}

The results in Table 2 show that a significant difference exists between age and majors. The results indicated that in terms of the different economic levels, Jiulongpo has the highest economic level among the three districts [37], and this condition may attract more young PHWs because of the higher salary. Moreover, most PHWs work in public health [6]. Apparently, economic level is a vital impact factor of the self-evaluation competency scores of PHWs. The economic level of Jiulongpo is higher than those of Qianjiang and Hechuan. Therefore, PHWs in Jiulongpo have a higher salary and a more positive working attitude than those in other districts, and thus they obtained the highest scores in competencies. Economic level can be a standard to measure public health development. It definitely made the PHWs obtain higher scores [38]. Therefore, improving the economic development of an area can improve the competencies of PHWs.

Competency is defined as "the ability to do something successfully;" that is, the ability to complete a job efficiently [22]. Table 3 shows the significant differences in the competencies of PMO, ACT, LRN, FAA, PLR, CMF, and CMC among the three sample districts. In terms of PMO, Jiulongpo is better than Hechuan at the economic level, and the scores of PHWs' competencies in Jiulongpo are higher than 
those of PHWs in Hechuan. According to the literature, PMO involves "performance to be tracked" and "performance to be enhanced." To some extent, PMO decides the public health working effect of PHWs, especially in township hospitals the working performance of which is associated with their economic level [11,39]. Reasonable and effective motivation mechanisms can improve health care performance by influencing the PHWs' behaviors [4]. Similar to the results, the higher the economic level is, the higher the competency scores of the PHWs.

The competencies of ACT of PHWs in Jiulongpo and Hechuan are higher than those of PHWs in Qianjiang. As McClelland argued, "competencies rather than intelligence" [8]. ACT includes initiative and impetus, that is, communicating with leaders and co-workers positively, and not delaying tasks. In this study, Jiulongpo township hospitals have the most excellent PHWs, who also have the highest scores in ACT competency. Although Hechuan township hospitals have poorly performing PHWs, these PHWs may have stronger competencies rather than intelligence. Thus, they could also obtain high scores in ACT competency.

The scores of LRN competency of PHWs in Jiulongpo were higher than those of PHWs in Qianjiang and Hechuan. No significant differences were found between Qianjiang and Hechuan. The reasons for this result are that Jiulongpo township hospitals have more excellent PHWs and that training and learning can enhance the skills of PHWs by learning from failed experiences [40,41]. A number of studies have shown similar results. According to Leung, competency-based training is the progression referenced to the demonstrated ability to perform certain tasks [42]. In our study, the scores of the LRN competency of PHWs in Jiulongpo were higher than those of the LRN competency of PHWs in the other two sample districts. Therefore, the PHWs in Jiulongpo district may obtain more effective training and experience.

The competencies of FAA, PLR, CMF, and CMC have significant differences among the three districts (1) $>$ (2), (1)>3); $p<0.01$ ). As shown in Table 3, the scores of competencies of FAA, PLR, CMF and CMC of PHWs in Jiulongpo were higher than those of the PHWs in Qianjiang and Hechuan. According to Al-Njjar and Alsouyf, FAA included "decision making" and "frustration tolerance", that is, adjusting the strategies for different cultures and people [43]. The capability in public health of the PHWs or the attitude of PHWs to residents' unreasonable response reflects public health in rural China [44]. Meanwhile, the working ability of PHWs indicates their knowledge and professional training in township hospitals. According to Sportsman and Fleig-Palmer, PLR involved "interpersonal influence" and "conflict management" [45,46], which verify how the PHWs in Jiulongpo District always take effective measures to solve problems. According to Wing, CMC means responsibility and consciousness. That is, communicating and establishing communication mechanism and CMF include positives communication, which predicts the demands and creates values for service objects [47]. In this study, the results prove that the more the PHWs are responsible and communicate with each other, the higher the scores they will obtain [48].

Rapidly developing the primary health care system and improving the level of primary health care quality are the vital tasks of the new health reform plans in China. Township hospitals are considered to be the bridge of primary health care and play a key role. Therefore, improving the competencies of PHWs in township hospitals is a priority. In this study, we selected 11 aspects based on a competency dictionary and related literature, with each aspect playing a significant role. ACH and PMO are the guides among the 11 aspects that provide their targets. Through DTO, ACT, LRN, FAA, TMW, PLR, 
$\mathrm{CMF}$ and $\mathrm{CMC}$ we can gain RSP and even acquire great achievement and better performance in enhancing the competencies of PHWs and improving public health performance.

The analysis in Table 4 indicate the relationship between the competencies and the factors using $t$-test and $A N O V A$. Further study on the impact factors using stepwise regression analysis is presented in Table 5. The results show five relevant factors of the PHWs' self-evaluation competency scores: economic level, age, years of working (yeas as a PHW), major, and title [49]. As previously mentioned, a higher economic level causes higher competency scores. As shown in Tables 4 and 5, the selfevaluation competency score of the PHWs in Jiulongpo is higher that of the PHWs in Qianjiang and Hechuan. A consistent relationship exists among "age", "years of working", and "title". This result indicates that the longer the years of working are, the older the PHWs and the higher their titles. Years of working is an important impact factor of competency [50]. The more years of work experience PHWs have, the higher their score in self-evaluation competencies [15]. Years of working are correlated with one's working experience. Therefore, the longer the years of working PHWs have, the more working experience they have. Working experience is a kind of education that can be obtained from outside the workplace or from the work itself. Training is usually a way of increasing working experience and improving competencies [51]. A number of studies have shown similar results. According to Liou, a significant difference exists between PHW's years in public health and clinical competencies, that is, the higher the number of working years of PHWs is, the higher their average score in public health than in clinical competencies [52]. A richer work experience obtains a higher self-evaluation competency score. The different titles of PHWs have different self-evaluation competency scores. Clearly, PHWs who have a higher title get a higher competency score. According to $\mathrm{Wu}$, public health institutions cannot supply high-quality service without a higher education level of their PHWs [5]. In other words, most PHWs with advanced titles have a higher educational level. In addition, a higher educational level adds to the rich working experience of PHWs so that they will become better at their job. PHWs who work in the public health service have a higher competency score than others. This findings indicates that PHWs who work in public health service possessed more professional knowledge than those who do not.

In terms of the majors of PHWs, the professional public health workers obtained the highest score among the five groups, and they play a vital role in the public health service of township hospitals [53]. A previous study showed that public health education has become part of medical education and that is has its own system and scale, and has played an important role in the public health field [48].

\section{Conclusions}

In this study, we were able to identify the competencies of PHWs in township hospitals in Chongqing Municipality in Western China that needed to be improved. The results of this study indicate some factors influencing the competencies of PHWs in township hospitals, such as economic level, age, years of working, title and major.

In light of the above, some proposals may be put forth. First, from the perspective of national policy, the Chinese government should establish related policies for township hospitals and primary health care. Second, the structure of PHWs should be optimized to provide more outstanding PHWs for the public health system in China. Last but not least, the knowledge, skills, and attitudes of PHWs should be 
improved through variety of training forms to improve the competencies of PHWs and the residents' satisfaction at the same time.

\section{Limitation}

The results came from 314 PHWs of 27 township hospitals from three districts in Chongqing Municipality (China). As the sample size is not large, it perhaps cannot represent the condition of all the township hospitals' PHWs in rural Western China. Nevertheless, the average number of PHWs of each township hospital is small according to the Chinese national situation, and Chongqing Municipality is not exempted, as the average number of PHWs (total number of full-time and part-time PHWs) in each township hospital is no more than 13. On the one hand, the sample size can represent the entire condition of PHWs of township hospitals in Chongqing Municipality. On the other hand, the results may reflect the condition of other PHWs of township hospitals in rural Western China to some extent. To ensure that our research result more precisely reflects the condition of PHWs of township hospitals in rural China, we will conduct a further study on township hospitals' PHWs in other regions such as the Middle regions and Eastern regions of China in the future. We designed the questionnaire by ourselves. Although it was tested by related professions, it still has problems. For instance, some questions need to be simplified. Moreover, the subjective answers of some PHWs to some questions led to partial information, which influenced the quality of the questionnaires more or less.

\section{Acknowledgments}

This project generously funded by the National Natural Science Foundation of China (NSFC) (project number: No.71273097). We would like to extend our sincere thanks to National Natural Science Foundation of China for the funding this research. We also highly appreciate the support of School of Medicine and Health Management, Tongji Medical College, Huazhong University of Science and Technology, the members of our research committee, and the assistance from township hospitals staffs.

\section{Author Contributions}

Zhifei He, Zhaohui Cheng and Zhanchun Feng contributed to the conception and design of the study. Zhifei He, Zhaohui Cheng and Hang Fu performed data analysis. Shangfeng Tang, Qian Fu, Haiqing Fang, Yue Xian and Hui Ming contributed to final linguistic review. All authors critically revised the final version of the manuscript and gave approval for publication.

\section{Conflicts of Interest}

The authors declare no conflict of interest.

\section{Abbreviations}

PHWs: Public Health Workers

PHS: Public Health Service

ACH: Achievement orientation

PMO: Performance orientation 
DTO: Detailed test objectives

ACT: Action

LRN: Learning

FAA: Flexible and adaptive

TMW: Teamwork

PLR: Public relation ability

CMF: Focusing on the service objectives

CMC: Communication

RSP: Responsibility

\section{Ethics Approval}

This study protocol was approved by the Research Ethics Committee of Tongji Medical College, Huazhong University of Science and Technology. All participants indicated that willingness to take part in this research project.

\section{References}

1. Tang, S.L.; Meng, Q.Y.; Chen, L.; Bekedam, H.; Evans, T.; Whitehead, M. Health System Reform in China tackling the challenges to health equity in China. Lancet 2008, 372, 1493-1501.

2. Kruk, M.E.; Porignon, D.; Rockers, P.C.; van Lerberghe, W. The contribution of primary care to health and health systems in low- and middle-income countries: A critical review of major primary care initiatives. Soc. Sci. Med. 2010, 70, 904-911.

3. Shi, L.; Macinko, J.; Starfield, B.; Politzer, R.; Wulu, J.; Xu, J. Primary care, social inequalities and all-cause, heart disease and cancer mortality in U.S. counties: A comparison between urban and non-urban areas. Public Health 2005, 119, 699-710.

4. Meng, Q.Y. The research of the motivation factors on essential public health workers. Chin. J. Health Policy 2012, 5, 4-5.

5. Wu, H.F.; He, P.; Al, L.P.E. The basic public health service in Chongqing. Chin. Gen. Pract. 2010, 16, 745-748.

6. Li, H.; Kong, P.; Meng, Q.Y. Impact factor associated with working behavior of public health workers in primary health care system. Chin. J. Health Policy 2015, 3, 6-11.

7. Bian, J.S.; Jing, X.X.; Sun, S. Current research in Chinese healthcare department concerning competency and the questions which should be considered. Chin. Health Serv. Manag. 2007, 7, 447-448.

8. McClelland, D.C. Testing for competence rather than "Intelligence". Am. Psychol. 1973, 28, 1-14.

9. Mclagan, P. Competencies models. Train. Dev. J. 1982, 34, 22-26.

10. Boyatzis, R.E. The Competent Manager: A Model for Effective Performance; Wiley: New York, NY, USA, 1982.

11. Spencer. L.; Spencer. S. Competencies at Work: Model for Superior Performance; Wiley: New York, NY, USA, 1993.

12. Youlong, G.; Wilkes, A.; Bloom, G. Health human resource development in rural China. Health Policy Plan. 1997, 12, 320-328. 
13. Dainty, A.R.J.; ASCE, M.; Cheng, M.; Moore, D.R. Competencies-based model for predicting construction project managers' performance. J. Manage. Eng. 2005, 21, 2-9.

14. Sherman, R.O.; Eggenberger, T.; Bishop, M.; Karden, R. Development of a leadership competencies model. J. Nurs. Adm. 2007, 2, 85-94.

15. Zhou, Z.H.; Wang, C.X.; Wang, J.J.; Yang, H.J.; Wang, C.; Liang, W.N. The knowledge, attitude and behavior about public health emergencies and the response capacity of primary care medical staffs of Guangdong Province, China. BMC Health Serv Res. 2012, 12, doi:10.1186/1472-6963-12-338.

16. Cheng, Y.; Zhou, Y.; Zhang, Y.; Jiang, X.; Xi, M.; Gan, K.; Ren, S. Study of knowledge and attitudes on medical abortion among Chinese health providers. Int. J. Gynecol. Obstet. 2012, 118, S28-S32.

17. Choi, J.S.; Kim, K.M. Factors influencing the self-perceived practice levels of professional standard competencies among infection control nurses in Korea. Am. J. Infect. Control. 2014, 42, 980-984.

18. Wu, D.; Wang, Y.; Lam, K.F.; Hesketh, T. Health system reforms, violence against doctors and job satisfaction in the medical profession: A cross-sectional survey in Zhejiang Province, eastern China. BMJ Open. 2014, 4, doi:10.1136/bmjopen-2014-006431.

19. Hsu, E.B.; Thomas, T.L.; Bass, E.B.; Whyne, D.; Kelen, G.D.; Green, G.B. Healthcare worker competencies for disaster training. BMC Med. Educ. 2006, 19, 1-9.

20. Katzy, B.; Crowston, K. Competencies Rally Processes in Virtual Organizations; Springer: Boston, MA, USA, 2007.

21. Lurie, S.J. History and practice of competencies-based assessment. Med Educ. 2012, 46, 49-57.

22. Brightwell, A.; Grant, J. Competencies-based training: Who benefits? Postgrad. Med. J. 2013, 89, 107-110.

23. Halbesleben, J.R.B.; Novicevic, M.M.; Harvey, M.G.; Buckley, M.R. Awareness of temporal complexity in leadership of creativity and innovation: A competencies-based model. Leadersh. $Q$. 2003, 14, 433-454.

24. Thompson, M.E.; Harver, A.; Eure, M. A model for integrating strategic planning and competence-based curriculum design in establishing a public health programme: The UNC Charlotte experience. Hum. Resour. Health. 2009, 7, doi:10.1186/1478-4491-7-71.

25. Wang, C.; Xiang, H.; Xu, Y.; Hu, D.; Zhang, W.; Lu, J.; Sun, L.; Nie, S. Improving emergency preparedness capability of rural public health personnel in China. Public Health 2010, 124, 339-344.

26. Li, L.; Yu-bo, L.; Yan, N.; Yan, C.; Jun, T.D.; Jun-feng, H. Intervention effects of knowledge and skills of the public to respond to public health emergencies in Sichuan province, China. Eval. Rev. 2014, 37, 140-157.

27. Chongqing Municipal Bureau of Statistics. Chongqing Statistical Yearbook 2014; China Statistics Press: Chongqing, China, 2014.

28. Patterson, F.; Ferguson, E.; Lane, P.; Farrell, K.; Martlew, J. Wells, A. A competency model for general practice: Implications for selection, training, and development. Brit. J. Gen. Pract. 2000, 50, 188-193.

29. Boam, R.; Sparrow, P. Designing and Achieving Competency; McGraw-Hill: London, UK, 1992.

30. Lucia, A.; Lepsinger, R. Competency Models: Pinpointing Critical Success Factors in Organizations; Jossey-Bass: San Francisco, CA, USA, 1999. 
31. Heijke, H.; Meng, C.; Ris, C. Fitting to the Job: The role of generic and vocational competencies in adjustment and performance. Labour Econ. 2003, 10, 215-229.

32. Leech, N.L.; Barrett, K.C.; Morgan, G.A. SPAA for Intermediate Statistics: Use and Interpretation; 2nd ed.; Lawrence Erlbaum Associates. Inc.: London, UK, 2005.

33. Bryman, A.; Cramer, D. Quantitative Data Analysis with SPSS for Windows: A Guide for Social Scientists; Routledge: London, UK, 1997.

34. Ning, N.; Kang, Z.; Jiao, M.L.; Hao, Y.H.; Gao, L.J.; Sun, H.; Wu, Q.H. Factors affecting emergency preparedness competencies of public health inspectors: A cross-sectional study in northeastern China. BMJ Open 2014, 4, doi:10.1136/bmjopen-2013-003832.

35. Cattell, R.B. The Meaning and Strategic Use of Factor Analysis. Handbook of Multivariate Experimental Psychology; Rand McNally: Chicago, IL, USA, 1966.

36. Kim, J.O; Mueller, C.W. Factor Analysis: Statistical methods and practical issues. In Factor Analysis and Related Techniques; Sage: London, UK, 1994.

37. Wang, X.W.; Xiong, J.Y.; Feng, Z.C. Influencing factors of human resources in western rural China. Med. Soc. 2009, 22, 25-27.

38. Zhong, Z.H.; Yan, J.; Liu, M. Analysis of the competencies of primary public health workers. J. Exam. Wkly. 2015, 65, 195-196.

39. Abraham, S.E.; Karns, L.A.; Show, K.; Mena, M.A. Managerial competencies and the managerial performance appraisal process. J. Manag. Dev. 2001, 20, 842-852.

40. Stewart, K.E.; Halverson, P.K.; Rose, A.V.; Walker, S.K. Public health workforce training: Application of the Council on Linkages' Core Competencies. J. Public Health Manag. Pract. 2010, 16, 465-469.

41. Grussing, P.G. Education and practice: Is competencies-based education closing the gap? Am. J. Pharm. Educ. 1984, 48, 117-124.

42. Leung, W.C. Competencies based medical training: Review. BMJ 2002, 325, 693-696.

43. Al-Njjar, B.; Alsouyf, I. Selecting the most efficient maintenance approach using fussy multiple criteria decision making. Int. J. Prod. Econ. 2003, 84, 85-100.

44. Chang, J.; Yu, N.; Meng, Q. Impact factors of the hard-working degree among essential public health workers. Chin. Health Policy 2012, 5, 17-21.

45. Sportsman, S.; Hamilton, P. Conflict management styles in the health professions. J. Prof. Nurs. 2007, 23, 157-166.

46. Fleig-Palmer, M.M.; Rathert, C. Interpersonal mentoring and its influence on retention of valued health care workers: The moderating role of affective commitment. Health Care Manag. Rev. 2015, 40, 56-64.

47. Wing, A.J. The social responsibility of physicians as agents of public health services. Ren. Fail 1996, 18, 425-431.

48. Zhou, H.; Zhang, W.; Zhang, S.; Wang, F.; Zhong, Y.; Gu, L.; Qu, Z.; Liang, X.; Sa, Z.; Wang, X.; et al. Health providers' perspectives on delivering public health services under the contract service policy in rural China: Evidence from Xinjian County. BMC Health Serv. Res. 2015, 15, doi:10.1186/s12913-015-0739-x. 
49. O'Keefe, K.A.; Shafir, S.C.; Shoaf, K.I. Local health department epidemiologic capacity: A stratified cross-sectional assessment describing the quantity, education, training, and perceived competencies of epidemiologic staff. Front. Public Health 2013, 1, doi:10.3389/fpubh.2013.00064.

50. Silverman, G.S.; Silverman, M.K. Skills, knowledge, and abilities of graduates from accredited environmental health science and protection undergraduate programs. J. Environ. Health. 2003, 65, 17-23.

51. Pfleger, D.E.; McHattie, L.W.; Diack, H.L.; McCaig, D.J.; Stewart, D.C. Views, attitudes and self-assessed training needs of Scottish community pharmacists to public health practice and competence. Pharm. World Sci. 2008, 30, 801-809.

52. Liou, S.R.; Chang, C.H.; Tsai, H.M.; Cheng, C.Y. The effects of a deliberate practice program on nursing students' perception of clinical competence. Nurs. Educ. Today 2012, 33, 358-363.

53. Zanolin, M.E.; Visentin, M.; Trentin, L.; Saiani, L.; Brugnolli, A.; Grassi, M. A questionnaire to evaluate the knowledge and attitudes of health care providers on pain. J. Pain Symp. Manag. 2007, $33,727-736$.

(C) 2015 by the authors; licensee MDPI, Basel, Switzerland. This article is an open access article distributed under the terms and conditions of the Creative Commons Attribution license (http://creativecommons.org/licenses/by/4.0/). 